\title{
Seeing Through a Different LENS: Can Applying a Learning Strategy to Video Viewing Deepen Self-Reflection of Pre-Service Teachers?
}

\author{
Michelle Chamblin \\ Molloy College, New York, USA \\ Email: mchamblin@molloy.edu
}

How to cite this paper: Chamblin, M. (2016) Seeing Through a Different LENS: Can Applying a Learning Strategy to Video Viewing Deepen Self-Reflection of PreService Teachers? Open Access Library Journal, 3: e3261.

http://dx.doi.org/10.4236/oalib.1103261

Received: November 28, 2016

Accepted: December 17, 2016

Published: December 21, 2016

Copyright $\odot 2016$ by author and Open Access Library Inc.

This work is licensed under the Creative

Commons Attribution International

License (CC BY 4.0).

http://creativecommons.org/licenses/by/4.0/

\begin{abstract}
The use of video for self-reflection in teacher preparation programs is used to promote self-reflection in knowledge, skills and dispositions for teaching. This study investigates the effect of a learning strategy used with video viewing to determine if the strategy aids in the thinking process which occurs while reflecting. A written selfreflection to a video was compared between 40 pre-service teachers that did not have access to the learning strategy and 25 pre-service teachers that were provided with a learning strategy. The results indicated that the learning strategy improved the quality of self-reflection responses and that learning strategies may be beneficial aids for metacognitive processes while self-reflecting.
\end{abstract}

\section{Subject Areas}

Education

\section{Keywords}

Video, Technology in Education, Reflection in Education, Teacher Education,

Learning Strategies, Dispositions, Pre-Service Teacher Training, Teacher Preparation

\section{Introduction}

There has been much research concerning the use of videos to enhance the professional development of pre-service teachers (Marsh \& Mitchell 2014 [1]; Bloomberg, Sherin, Renkl, Glogger, \& Seidel 2013 [2]). In the higher education classroom, it is common to use videos as an instructional tool to spark discussion and ignite reflection. Viewing videos provides opportunities for pre-service teachers to connect theory to practice, as 
they view situations, scenarios and teaching in the classroom by others or even themselves (Hiebert, Gallimore \& Stigler, 2002 [3]; Borko et al., 2008 [4]). Observing these situations and scenarios from a viewing distance can serve as a platform for critical analysis. The hopeful outcome of this analysis is for the pre-service teacher to reflect upon the concepts, theories and actions, sifting the information to filter that which will enhance their potential and having a clear understanding for that which is discarded.

\section{Purpose}

Video watching is used as a tool and like any tool can be sharpened for higher levels of effectiveness. How can educators make the best use of videos so that students are reflecting on the information presented and then able to clearly articulate this information? A guide to this type of thinking or meta cognitive processes could be paired with video viewing to achieve this. Thus this line of inquiry lead to the purpose of this study which is to determine if a learning strategy paired with video viewing would deepen the reflections of pre service teachers. This would be evidenced in their self-reflection response after viewing the videos.

\section{Research Background}

\subsection{Self-Reflection}

Self-reflection is an immersion into the thought process whereby the pre-service teacher ponders the big questions and begins etching out her identity as a professional. Using videos as a teaching tool may be a useful to engage self-reflection but two issues are highlighted in the research that may compromise the effectiveness of this practice. First, Bloomberg, Sherin, Renkl, Glogger \& Seidel [5] point out that there is little research to determine which is the most effective way to use videos. There is no definitive answer as to how to implement videos, what to do with them other than there should be a clearly defined goal for why the teacher selects using a video to supplement instruction. Secondly, Ruth [6] Reid [7], and Kotzee [8] point out the need for self-reflection to be better defined. Self-reflection can be defined in many ways but because it is essentially a cognitive process that is embodied by the individual it is difficult to define and measure self-reflection. Therefore when using videos as a tool for self-reflection the following questions are raised: when using videos, how does one use it to engage students in selfreflection? Is there a strategy can be used while students are viewing the video to assist their reflective thinking?

In many of the studies on self-reflection, pre-service teachers watched a video and were asked to write a journal or self-reflective response as an assessment measure of their self-reflective thinking (Marsh \& Mitchell, 2013 [1]). The videos discussed in studies were mostly teaching videos. Teaching videos demonstrate classroom situations and scenarios where pre-service teacher can analyze what is happening in a classroom scenario. The self-reflection requested is connected to the question, what would you do if you were in this situation? Watching the video provides the pre-service teacher with 
an opportunity to examine elements that are occurring and connect theory to practice as he dissects the actions and articulates what he would have done and why based on research and best practices in education. Another situation is when pre-service teachers video their own teaching and then view it. They are then asked to analyze their performance and its impact on learning. This practice has become very popular and in some places, submission of a videotaped segment of the pre-service teacher's performance is required for a teaching license.

However, there are other types of videos shown in the classroom which are used for self-reflection. These videos are used to dig into the pre-service teacher's beliefs and dispositions for teaching. For example, in the area of special education, pre-service teachers are required to understand how disability affects the child's life and family. The pre-service teacher has to believe that all students can learn and that the student is greater than the disabling condition. Using videos that show students with disabilities going through their daily challenges and struggles are used so that the pre-service teacher can understand the complexities of the disability and its impact on the individual. These complexities are brought into the teaching situation and the teacher should have beliefs and dispositions to embrace these complexities. Teaching and assessing beliefs isn't as straight forward as assessing the pre-service teacher's ability to write a lesson plan, or teach a lesson on vocabulary. Self-reflecting on the act of teaching is also straighter forward than having pre-service teachers self-reflect on their beliefs, attitudes and dispositions for teaching after viewing a video. Although this is a complex process, using videos may be an essential tool for the pre service teacher to self-reflect on the difficult situations that will challenge him to evaluate his thoughts.

Cultivating and assessing dispositions for teaching is a process that is required of teacher education programs. According to the United States National Council for the Accreditation of Teacher Education [9], "Dispositions for Teaching" are defined as:

"Professional attitudes, values, and beliefs demonstrated through both verbal and non-verbal behaviors as educators interact with students, families, colleagues, and communities. These positive behaviors support student learning and development.

The values, commitments and professional ethics that influence behaviors toward students, families, colleagues and communities and affect student learning, motivation and attitudes related to values such as caring, fairness, honesty, responsibility and social justice."

\subsection{Dispositions for Teaching}

Prior to becoming an in-service teacher, pre-service teachers are presented with dispositions for which they should be reflecting on while taking courses to ensure that they have the dispositions prior to exiting a teacher preparation program. For example, at Molloy College (Rockville Centre, New York, USA) pre-service teachers receive the following list of disposition for which they are to self-reflect and at particular check points during their time enrolled in the program; these dispositions are assessed, usually through self-reflection responses and teacher observations. The following are a list of 
the dispositions provided:

Molloy College Dispositions for Teaching [10]

1) Believes all children can learn.

2) Embraces responsibilities and duties associated with the role of teacher.

3) Approaches intellectual pursuits with integrity and open mindedness with respect to one's own teaching practices.

4) Values and nurtures students' intellectual, aesthetic and social growth.

5) Possesses enthusiasm and passion about teaching and learning with a commitment to students and their learning.

6) Values and models respect for self, family, educative institutions, and community.

7) Addresses differences in learning styles and diversity.

8) Evaluates and reflects on professional practice to make informed decisions regarding the use of technology in support of student learning and academic honesty.

9) Fosters an appreciation of multiculturalism, creating a climate of social justice and respect.

10) Evaluates and reflects on professional research and proven best practice to make informed decisions.

11) Reflects on, uses, and implements a variety of assessments to improve effective practice.

12) Values inquiry and higher order thinking

These dispositions are limited and there are attitudes and beliefs in addition that are implied. The dispositions provided by the institution are connected to professional standards that guide the teaching profession. The professional standards articulate expectations that go beyond the science of teaching but are subtly infused with dispositions that must be acquired during training and maintained to become a professional teacher.

In teacher preparation for special education in the United States, for example, the Council for Exceptional Children [11] has national standards that use words and phrases such as: provide meaningful learning experiences, create inclusive and culturally responsive classrooms, provide emotional wellbeing, positive social interactions, advocate, have integrity, collegiality and respect. These standards require that the preservice teacher engage in introspection and analyze his beliefs about students who are different and what it takes to teach well. The charge extends beyond the parameters of knowing subject matter; rather it entails developing dispositions which are supported by beliefs. For example, in order to create a culturally responsive classroom, there are many underlying beliefs about culture that the pre-service teacher may have that may results in the execution of a culturally responsive classroom. To the contrary, if the beliefs and dispositions are absent, the pre-service teacher may not have the capacity to fulfill the standards. Therefore it behooves teacher education programs to invest in assessment of dispositions of pre-service teachers. Knowing how to assess dispositions and beliefs can be elusive; however, having students self-reflect on videos that raise the hard issues may be a start. The self-reflection process can be used to help the pre-service 
teachers and teacher educators cultivate and assess beliefs and dispositions.

The nature of writing a self-reflection under these circumstances may be difficult for the pre-service teacher. Instruction in how to think about your beliefs, dispositions and attitudes is not a general course offering but conceptually woven in course work and experiences. Therefore writing a self-reflection based on a video may need to have specific instruction and/or a strategy to assist with how to think about the process of thinking while watching the video.

\subsection{Learning Strategies}

One researched based strategy that has demonstrated effectiveness with helping individuals improve their thinking about thinking is learning strategies (Dreshler, Ellis, Lenz 1996 [12]; Bulgren, Schumaker \& Dreshler 1994 [13]; Dreshler \& Shumaker 1988 [14]; Hock, Dreshler \& Shumaker 1993 [15]). Learning strategies are designed so that the learner can think through a unit of information or task, with guidance on how and what he should be thinking about. Learning strategies foster metacognition. Learning strategies have been used to help with tasks such as how to paraphrase a written passage, how to analyze and interpret a visual aid, how to figure out an unknown word when reading, how to organize materials that need to be memorized and how to prepare for a test. These are just a few examples but what all of these have in common is that the learning strategy is used to help the learner think about the task and focus on the "how" of the mental processes rather than the content or the "what" of instruction. In the case of watch videos, pre service teachers can either focus "what" is happening in the video or focus on the "how" of how to think about what is being depicted in the video and how they feel about the content taking it to a deeper level.

\subsection{Deepening Self-Refection by Level: Descriptive, Evaluative and Integration}

Bloomberg [2] analyzed self-reflections and describes this deeper level. Self-reflection responses were as differentiated into different levels. On the first level the viewer's reflection was descriptive in that they write about what they have viewed without making judgements. The second level was evaluation where the viewer reflects on what was observed and makes judgments about student learning. The third level was Integration where the viewer linked professional knowledge to what was observed and made inferences. Again, these studies primarily used classroom scenario videos and the types of videos suggested in this process are different; however, it is evident that self-reflective responses can be assessed from a surface description, evaluation and then integration. This same approach can be applied to viewing videos that raise difficult situations and challenge students to self-reflection on their dispositions.

It may be possible to get in-service teacher to self-reflect on an integration level. Providing a learning strategy while observing the video may be an effective strategy. Although there are many studies concerning the effectiveness of students with and without disabilities in the k-12 population, very few studies examine learning strategies with 
post-secondary students or graduate students.

\section{Creating a Learning Strategy}

For the purpose of this study the researcher, who is also the teacher of the pre-service teachers, created a learning strategy titled LENS using the steps detailed in Teaching Adolescent Students with Disabilities (Dreshler et al., 1996 [14]). The five design features which were used are as followed:

1) The steps of the learning strategy are encapsulated in a remembering system.

2) The wording of each step in the remembering system is simple and brief.

3) Each step of the learning strategy begins with an action word.

4) There should be on more than seven steps.

5) Terms used in the strategy shouldn't be unfamiliar or overly complicated.

The term Lens was used because of its association to a tool that helps one view from various perspectives. Following is the teacher created learning strategy:

LENS Strategy, created by Michelle Chamblin

L: LEARN

Write notes about three things you learned.

What were the big ideas?

What philosophical or theoretical connections can you make?

E: EXPECTATIONS

Analyze how has viewing this changed or reinforced what you expect from yourself when working with diverse students.

\section{$\mathrm{N}$ : NEEDS}

Define the knowledge, skills and dispositions (attitudes and beliefs) that a teacher needs to bring to the situation observed

S: SPOKE

Evaluate one segment of this video that spoke to you. What was it about this segment that caused this?

Spoke $=$ enlighten, thought provoking, life confirming, cause you to unravel

\section{Experiment}

As part of a course assignment, pre-service teachers watched two videos. One video was about the story of a person who had a disability and how it affected his life functioning, daily living skills, family, relationships, education, goals, career prospects and selfdetermined pursuits. The second video featured a prominent administrator and advocate in the field of special education. In this video he shares insights, advice, research and strategies that he believes works well for students with Learning Disabilities. In addition he discusses the dispositions needed by aspiring teachers.

The students watched the videos during the class sessions and afforded two weeks to submit the reflection. A 3 point rubric and instructions were provided with 3 being the highest level. The instructions for the assignment read: As of a result of watching the two videos in class, write a self-reflection examining your reactions and thoughts about 
the videos. Examine the knowledge, skills and dispositions for teaching student with disabilities and what the teacher needs to bring to the classroom. Self-reflect on your dispositions for teaching and what you would do or bring to the situations viewed.

Student self-reflections were collected over four semesters. During the first semester 20 pre-service teachers received the instructions and the rubric. Their self-reflections were collected, and graded based on the 3 point rubric. The following semester 20 pre-service teachers received the same instructions and rubric. Their self-reflections were collected and graded based on the 3 point rubric. In the third semester, 14 pre service teachers received the same instructions and rubric. In addition they were provided the LENS learning strategy which they could use while watching the videos. During the $4^{\text {th }}$ semester 11 pre-service teachers were given the same directions and rubrics and also provided the LENS strategy. Their self-reflection was collected and graded based on the 3 point rubric. Students 'self-reflections were categorized into two group; Group A for the students that had the instructions and rubric, Group B for the students that had the instructions, rubric and LENS strategy.

Qualitative analysis was used to examine the self-reflections. Three categories of data were collected which consisted of the:

1) Rubric score.

2) Coding procedure-which counted the number of times the paper mentioned a phrase or term connected with dispositions for teaching, attitudes or beliefs connected to the pre-service teachers' inventory of skills. These statements could have been either the dispositions they believe they have or need to cultivate. If the statement was a remark about what teachers' need in general without connecting it to the self, then it was not counted in the coding.

3) Number of papers in the descriptive, evaluative and integration category. Using modified Bloomberg et al. descriptions, the papers were judged to be either at: a descriptive level, evaluative level or integration level. At the descriptive level the pre service teacher's self-reflection comprise mostly of descriptions of what he watched from the video with comments on theory and practice. At the evaluative level, the pre-service teacher's self-reflection comprise of descriptions but moves into making judgments about the scenes and scenarios about theory and practice and what skills and dispositions teachers need in a general sense. At the integration level the pre-service teacher identifies the relevant features from a scene and connects it to theory, practice and comments on the skills, dispositions, attitudes and/or beliefs needed but furthermore discusses himself in connection to these concepts.

\section{Results and Conclusions}

Group A earned an average rubric score of 2.1 and Group B earned an average rubric score of 2.7. For the coded responses Group A's average was 5 statements, whereas group B was 12 statements. Group A had 10 self-reflections which were mostly descriptive, 26 evaluative and 4 which demonstrated integration. The results are summarized as follows: 


\begin{tabular}{cccc}
\hline $\begin{array}{c}\text { Group } \\
\text { Assignment }\end{array}$ & $\begin{array}{c}\text { Average Rubric } \\
\text { Score }\end{array}$ & $\begin{array}{c}\text { Average Coded } \\
\text { Responses }\end{array}$ & $\begin{array}{c}\text { Number of Descriptive, Evaluative } \\
\text { and Integration }\end{array}$ \\
\hline Group A $=\mathrm{n} 40$ & 2.1 & 5 & $\mathrm{D}=10, \mathrm{E}=26, \mathrm{I}=4$ \\
Group B $=\mathrm{n} 25$ & 2.7 & 12 & $\mathrm{D}=0, \mathrm{E}=3, \mathrm{I}=22$ \\
\hline
\end{tabular}

Performance on the rubric was varied but one trend stood out. Group B consistently achieved a score of 3 on the section of the rubric which read: student fully examines personal practice and provides examples. It is noteworthy to mention that the submissions from Group B were more introspective and the reflections focused more on personal practices whereas the Group A discussed pedagogy without connecting it to beliefs and dispositions at the same level of integration that was produced by Group B. Submissions written by the Group B were more often written in first person, shared personal experiences as examples to support their discussion of a particular concept or scenes from the videos that "spoke" to them. The submissions from Group A were written more in third person and included references from other articles or texts to support their points. Submissions were more in line with scholarly expectations that were not requested and the integration of their knowledge, skills and disposition was lacking.

It is interesting that Group A did not write about ideas, concepts or scenes that were enlightening, shock provoking, life confirming or that stood out in any particular way. This one dimension which was on the LENS strategy was in every submission from Group B and given a large focus. Many submissions from Group B used this point as an opening to their papers and as a vehicle to connect their personal experiences, thoughts, beliefs and comments concerning their disposition to the scenes that spoke to them.

In conclusion, the data suggest that the LENS strategy was effective at helping pre-service teachers use metacognitive skills while viewing a video. A learning strategy may have assisted in deeper connections with the video and self-reflection as their written responses seemed to have demonstrated this in a measurable outcome. There are many limitations to this study, one being that the small sample and other variables such as the students' GPA and writing expertise in this area prior to the study. Replication of this study is needed and continued research in using learning strategies with students at all levels, including post-secondary, should continue.

One particular point for discussion is whether the learning strategy helped preservice teachers with thinking about thinking or did the learning strategy simply clarify the expectation of the teacher. Perhaps the learning strategy was a tool more necessary for the teacher to convey how she desired students to think about the videos; that in fact, learning strategies may be used effectively for other purposes is intriguing. This unintended question raised in the study also brings about the cause for further investigation in this line of inquiry.

\section{References}

[1] Marsh, B. and Mitchell, N. (2014) The Role of Video in Teacher Professional Development. Teacher Development, 10, 403-417. https://doi.org/10.1080/13664530.2014.938106 
[2] Bloomberg, G., Sherin, M.G., Renkl, I.G. and Seidel, T. (2013) Understanding Video as a Toll for Teacher Education: Investigating Instructional Strategies to Promote Reflection. Springer Science and Business, 42, 443-463.

[3] Hiebert, J., Gallimore, R. and Stigler, J. (2002) A Knowledge Base for the Teaching Profession: What Would It Look Like and How Can We Get One? Educational Researcher, 31, 3-15. https://doi.org/10.3102/0013189X031005003

[4] Borko, H., Jacobs, J., Eiteljorg, E. and Pittman, M.E. (2008) Video as a Tool for Fostering Productive Discussions in Mathematics Professional Development. Teaching and Teacher Education, 24, 417-436. https://doi.org/10.1016/j.tate.2006.11.012

[5] Bloomberg, G., Sherin, M.G., Renkl, I.G. and Seidel, T. (2013) Understanding Video as a Toll for Teacher Education: Investigating Instructional Strategies to Promote Reflection. Springer Science and Business, 42, 443-463.

[6] Ruth, D. (2014) Teaching Strategy: Reflections on Professional Practice. Teaching in Higher Education, 19, 254-265. https://doi.org/10.1080/13562517.2013.860100

[7] Reid, J.A. (2011) A Practice Turn for Teacher Education? Asia-Pacific Journal of Teacher Education, 39, 293-310. https://doi.org/10.1080/1359866X.2011.614688

[8] Kotzee, B. (2012) Private Practice: Exploring the Missing Social Dimension in Reflective Practice. Studies in Continuing Education, 34, 5-16.

https://doi.org/10.1080/0158037X.2012.660521

[9] http://ncate.org/Standards/UnitStandards/Glossary/tabid/477/Default.aspx\#P

[10] http://www.molloy.edu/academics/undergraduate-programs/education/dispositions-for-tea ching

[11] http://www.cec.sped.org/standards/

[12] Deshler, D., Ellis, E. and Lennz, B. (1996) Teaching Adolescents with Learning Disabilities: Love Publishing Co., Denver, CO.

[13] Bulgren, J.A., Schumaker, J.B. and Dressler, D.D. (1995) Effectiveness of a Concept Teaching Routine in Enhancing the Performance of LD Students in Secondary-Level Mainstream Classes. Learning Disability Quarterly, 11, 3-17. https://doi.org/10.2307/1511034

[14] Dreshler, D.D. and Schumaker, J.B. (1988) An Instructional Model for Teaching Students How to Learn. In: Graden, J.L., Zins, J.E. and Curtis, M.J., Eds., Alternative Educational Delivery Systems: Enhancing Instructional Options for All Students, NASP, Washington DC, 391-411.

[15] Hocks, M.F., Dreshler, D.D. and Schumaker, J.B. (1993) Learning Strategy Instruction for at Risk and Learning Disabled Adults: The Development of Strategic Learners through Apprenticeship. Preventing School Failure, 38, 43-49.

https://doi.org/10.1080/1045988X.1993.9944294 
Submit or recommend next manuscript to OALib Journal and we will provide best service for you:

- Publication frequency: Monthly

- 9 subject areas of science, technology and medicine

- Fair and rigorous peer-review system

- Fast publication process

- Article promotion in various social networking sites (LinkedIn, Facebook, Twitter, etc.)

- Maximum dissemination of your research work

Submit Your Paper Online: Click Here to Submit

Or Contact service@oalib.com 